\title{
IL-6 and miR-1271 expression levels in elderly and young gastric cancer patients and correlation analysis with prognosis
}

\author{
SHIXIONG LIU ${ }^{1}$, YUN ZHOU $^{1}$, LI ZHAO ${ }^{2}$, JING WANG ${ }^{1}$, \\ RUI JI $^{3}$, YIQING WANG ${ }^{1}$, JIYIN WU ${ }^{1}$ and XIANG YAN ${ }^{1}$ \\ ${ }^{1}$ Department of Geriatrics (II), The First Hospital of Lanzhou University, Lanzhou, Gansu 730000; \\ ${ }^{2}$ Department of Ultrasound, Affiliated Hospital of Gansu University of Chinese Medicine, Lanzhou, Gansu 730020; \\ ${ }^{3}$ Department of Gastroenterology, The First Hospital of Lanzhou University, Lanzhou, Gansu 730000, P.R. China
}

Received November 14, 2018; Accepted March 18, 2019

DOI: 10.3892/ol.2019.10230

\begin{abstract}
Differences in inflammatory factors IL-6 and miR-1271 expression levels between elderly and young gastric cancer patients were investigated. A retrospective analysis of 146 cases of gastric cancer tissue and normal fresh tissue specimens diagnosed in The First Hospital of Lanzhou University from January 2013 to January 2015, was performed. Patients aged $\geq 60$ years were the elderly group (76 cases), and patients $\leq 40$ years were the youth group (70 cases). RT-qPCR was used to detect the relative expression levels of IL-6 and miR-1271, and Kaplan-Meier for a postoperative 3-year survival analysis of young and elderly gastric cancer patients. The expression level of IL-6 and miR-1271 was significantly higher in young gastric cancer tissues than that in elderly gastric cancer tissues $(\mathrm{P}<0.001)$. The expression levels of IL-6 and miR-1271 were correlated with age, tumor size, lymph node metastasis, distant metastasis, clinical stage and differentiation degree of gastric cancer patients $(\mathrm{P}<0.05)$. The 3 -year overall survival rate of patients with a low expression of IL-6 and miR-1271 was better than that of patients with a high expression in young and elderly gastric cancer $(\mathrm{P}<0.05)$. IL-6 was highly expressed but miR-1271 expression was low in gastric cancer tissues. The 3-year overall survival rate of patients with the low expression of IL-6 was better than that of patients with the high expression in young and elderly gastric cancer. The high expression of miR-1271 was better than that of patients with the low expression in young and elderly gastric cancer. Findings of the present study provide data support for the clinical evaluation of differences between young and elderly gastric cancer and their prognosis.
\end{abstract}

Correspondence to: Dr Yun Zhou, Department of Geriatrics (II), The First Hospital of Lanzhou University, 418 Guazhou Road, Lanzhou, Gansu 730000, P.R. China

E-mail: zhouyun467@163.com

Key words: IL-6, miR-1271, elderly gastric cancer, young gastric cancer, prognosis

\section{Introduction}

Gastric cancer, a common digestive tract tumor worldwide, has high grade malignancy and mortality $(1,2)$. Its age of onset is mostly around 60 years, and the incidence increases with age. It has been shown that the incidence of cancer in today's society is tending to be younger (3). In addition, the clinical and pathological features of elderly gastric cancer are quite different from those of young gastric cancer (4). Elderly gastric cancer usually has low-grade malignancy and high differentiation, making the prognosis of elderly gastric cancer patients slightly better than that of young gastric cancer patients (5). The physical fitness of the youth population is mostly good, with a small number of physical examinations and medical treatments per year; thus, the proportion of young patients diagnosed as advanced gastric cancer at the time of initial diagnosis is higher (6). However, the current claim that the prognosis of elderly gastric cancer is superior to that of young gastric cancer remains controversial.

It has been reported in the literature that miRNAs are involved in cell proliferation, apoptosis, differentiation and embryonic development (7). In recent years, medical workers have gradually taken the relationship between miRNAs and tumors as a research hotspot (8). However, miR-1271 has rarely been studied on tumors. Only a few related studies have shown that miR-1271 has a low expression in non-small cell lung cancer and is correlated with the poor prognosis of cancer (9).

Having diverse and complex functions, IL-6 plays an important role in tumor processes, inflammation and immune responses (10). IL-6 has been reported in the literature to be used as an indicator to predict the prognosis of gastric cancer (11). Currently, the population of the world is developing with an aging trend (12), and chronic inflammation is closely related to the increase of age. Inflammation can promote cell aging, which in turn can produce inflammatory factors $(13,14)$. According to reports in the literature, the high level of pro-inflammatory factor interleukin-6 (IL-6) in the body, associated with cognitive dysfunction, cardiovascular disease and brain atrophy in the elderly, can be used as a reference standard for inflammatory aging (15-17). 
The aim of this study was to investigate differences in the inflammatory factors IL-6 and miR-1271 expression levels between elderly and young gastric cancer patients and their correlation with prognosis, providing data support for the clinical evaluation of the prognosis of gastric cancer.

\section{Materials and methods}

General information. A retrospective analysis of each of 146 cases of gastric cancer tissue and normal fresh tissue specimens at $50 \mathrm{~mm}$ adjacent to the cancer, surgically resected and first diagnosed in The First Hospital of Lanzhou University (Lanzhou, China) from January 2013 to January 2015 , was performed. The age range was 28-75 years, and patients $\geq 60$ years were placed in the elderly group (76 cases), while those $\leq 40$ years in the youth group (70 cases). There was a significant difference between the two groups in age $(\mathrm{P}<0.001)$, but no significant difference in sex, tumor size, lymph node metastasis, distant metastasis, clinical stage and differentiation degree $(\mathrm{P}>0.05)$. Specimens were immediately stored in liquid nitrogen after resection, and then transferred to a refrigerator at $-80^{\circ} \mathrm{C}$. All cancer tissue specimens were confirmed by gastroscope pathology. According to the results of $\mathrm{CT}$, radical gastrectomy could be performed. Adjacent tissues were confirmed without obvious cancer cells and inflammatory cell infiltrations. In this study, patients aged 40-60 years with gastric cancer were excluded. None of the patients had a past history of tumors, liver, kidney, other organ dysfunction, abnormal bleeding or coagulation disorder dysfunction. Patients were included with complete medical records and follow-up data and without radiotherapy, chemotherapy or other anticancer treatments before operation (Table I).

The study was reviewed by the Ethics Committee of The First Hospital of Lanzhou University. All patients and their families were informed and signed the consent form.

Reagents and instruments. ELISA kit of IL-6 was purchased from Beijing Yuetai Technology Co., Ltd., Beijing, China; TRIzol reagent for RNA extraction from Shanghai Pufei Biotechnology Co., Ltd., Shanghai, China; TaqMan MicroRNA assay from Applied Biosystems, Foster City, CA, USA; Nanodrop 2000 UV spectrophotometer from Thermo Fisher Scientific, Inc., Waltham, MA, USA; Countess II FL Automated Cell Counter real-time PCR instrument from Applied Biosystems; and Antus PHOMO automatic microplate reader from Jinan Yuteng Biotechnology Co., Ltd., Jinan, China.

Total RNA extraction. One-step extraction was used to extract the total RNA from gastric cancer tissues and adjacent tissues with TRIzol reagent. The specific steps were in strict accordance with the protocol. The Nanodrop 2000 UV spectrophotometer was used to detect the extracted RNA concentration and purity, and agarose gel electrophoresis to detect its integrity.

Reverse transcription reaction. Reverse transcription was performed on the extracted RNA to obtain cDNA that was used as a template to carry out experiments. Primer sequences were designed and produced by Baoriyi Biotechnology (Beijing) Co., Ltd., Beijing, China, with $U 6$ as an internal reference gene in this experiment. A total of $20 \mu \mathrm{l}$ of the reverse transcription system was used as follows: $2 \mu 1$ of total RNA, $1 \mu 1$ of miRNA RT enzyme mix, $10 \mu \mathrm{l}$ of $2 \mathrm{X}$ TS miRNA reaction mix, and RNase-free water supplemented to $20 \mu \mathrm{l}$. Reaction conditions were: incubation at $37^{\circ} \mathrm{C}$ for $1 \mathrm{~h}$ then mixing, heating at $85^{\circ} \mathrm{C}$ for $5 \mathrm{sec}$ to inactivate RT enzyme mix, and the synthesized cDNA was stored at $4^{\circ} \mathrm{C}$.

$R T-q P C R$ detection of gene expression. A total of $20 \mu 1$ of the real-time PCR system was prepared in accordance with the protocol: $1 \mu \mathrm{l}$ of cDNA (dilution at a ratio of $1: 10$ ), $0.4 \mu \mathrm{l}$ of forward primer, $0.4 \mu \mathrm{l}$ of Universal miRNA qPCR Primer, $10 \mu \mathrm{l}$ of Tip Green qPCR SuperMix, and $\mathrm{ddH}_{2} \mathrm{O}$ supplemented to $20 \mu \mathrm{l}$. PCR amplification was performed using a Countess II FL Automated Cell Counter real-time PCR instrument. Reaction conditions were: at $94^{\circ} \mathrm{C}$ for $30 \mathrm{sec}$, at $94^{\circ} \mathrm{C}$ for $5 \mathrm{sec}$, and at $60^{\circ} \mathrm{C}$ for $30 \mathrm{sec}$, for a total of 40 cycles. The PCR product was stored at $4^{\circ} \mathrm{C}$, with $U 6$ as a reaction internal reference gene. Each group of samples was repeated 3 times. The $2^{-\Delta \mathrm{Cq}}$ method was used to analyze the expression level of miR-1271 in specimens (18). Primer sequences are shown in Table II.

ELISA detection of IL-6 expression level. Gastric cancer tissue $(100 \mathrm{~g})$ was taken, with $5 \mathrm{ml}$ of PBS solution added, to prepare homogenate in an ice-water suspension. It was centrifuged at $10,600 \mathrm{x}$ for $5 \mathrm{~min}$ at $4{ }^{\circ} \mathrm{C}$, with the supernatant taken for use. ELISA was used to detect IL- 6 levels in gastric cancer tissues and adjacent tissues, and an automatic microplate reader to detect the OD value of each well at a wavelength of $450 \mathrm{~nm}$, to calculate IL-6 concentration. The specific operation was carried out in strict accordance with the protocol. The determination was repeated 3 times to obtain the average value.

Statistical analysis. SPSS 21.0 statistical software package (Shanghai Kabei Information Technology Co., Ltd., Shanghai, China) was used to statistically analyze the data. Measurement data are expressed as mean \pm standard deviation (mean \pm SD). Analysis of variance was used for measurement data in accordance with the normal distribution, Kaplan-Meier for survival analysis, and log-rank test for comparison of the survival rate. $\mathrm{P}<0.05$ was considered to indicate a statistically significant difference.

\section{Results}

Expression levels of IL- 6 and miR-1271 in gastric cancer and adjacent tissues. The expression level of IL-6 was significantly higher in young and elderly gastric cancer tissues than that in adjacent tissues, with a statistically significant difference $(\mathrm{P}<0.001)$. That of IL-6 was significantly lower in young gastric cancer tissues than that in elderly gastric cancer tissues, with a statistically significant difference $(\mathrm{P}<0.001)$.

The expression level of miR-1271 was significantly lower in young and elderly gastric cancer tissues than that in adjacent tissues, with a statistically significant difference $(\mathrm{P}<0.001)$. That of miR-1271 was significantly higher in young gastric 
Table I. Comparison of general information between the two groups of patients [n (\%)].

\begin{tabular}{|c|c|c|c|c|}
\hline Factor & Elderly group $(n=76)$ & Youth group $(n=70)$ & $\mathrm{t} / \chi^{2}$ value & P-value \\
\hline Age & $68.72 \pm 5.66$ & $30.54 \pm 8.83$ & 31.35 & $<0.001$ \\
\hline Sex & & & 0.104 & 0.863 \\
\hline Male & $48(63.16)$ & $46(65.71)$ & & \\
\hline Female & $28(36.84)$ & $24(34.29)$ & & \\
\hline Tumor size & & & 0.615 & 0.506 \\
\hline$\geq 5 \mathrm{~cm}$ & $32(42.11)$ & $34(48.57)$ & & \\
\hline$<5 \mathrm{~cm}$ & $44(57.89)$ & $36(51.43)$ & & \\
\hline Lymph node metastasis & & & 1.329 & 0.320 \\
\hline Yes & $34(44.74)$ & $38(54.29)$ & & \\
\hline No & $42(55.26)$ & $32(45.71)$ & & \\
\hline Distant metastasis & & & 2.520 & 0.151 \\
\hline Yes & $19(25.00)$ & $26(37.14)$ & & \\
\hline No & $57(75.00)$ & $44(62.86)$ & & \\
\hline Clinical stage & & & 1.168 & 0.312 \\
\hline $\mathrm{I}+\mathrm{II}$ & $49(64.47)$ & $39(55.71)$ & & \\
\hline III+IV & $27(35.53)$ & $31(44.29)$ & & \\
\hline Differentiation degree & & & 1.989 & 0.173 \\
\hline Low-medium & $52(68.42)$ & $40(57.14)$ & & \\
\hline High & $24(31.58)$ & $30(42.86)$ & & \\
\hline
\end{tabular}

Table II. miR-1271 primer and internal reference sequence.

\begin{tabular}{lll}
\hline Gene name & \multicolumn{1}{c}{ Upstream primer } & \multicolumn{1}{c}{ Downstream primer } \\
\hline$m i R-1271$ & 5'-CAGCACTTGGCACCTAGCA-3' & 5'-TATGGTTGTTCTCCTCTCTGTCTC-3' \\
$U 6$ & 5'-CTCGCTTCGGCAGCACA-3' & 5'-AACGCTTCACGAATTTGCGT-3' \\
\hline
\end{tabular}

cancer tissues than that in elderly gastric cancer tissues, with a statistically significant difference $(\mathrm{P}<0.001)$ (Table III).

Correlation of IL-6 and miR-1271 expression levels with clinical and pathological features. The expression levels of IL-6 and miR-1271 were not significantly correlated with sex ( $\mathrm{P}>0.05)$, but correlated with age, tumor size, lymph node metastasis, distant metastasis, clinical stage and differentiation degree of gastric cancer patients $(\mathrm{P}<0.05)$. The expression level of IL- 6 was high, but that of miR-1271 was low in patients with older age, larger tumor size, lymph node metastasis, distant metastasis, the clinical stage of III-IV and low differentiation degree (Table IV).

Correlation of expression levels of IL- 6 and miR-1271 with young and elderly gastric cancer. The median expression levels of IL-6 and miR-1271 in young gastric cancer patients were $3.11 \pm 0.21$ and $1.84 \pm 0.14$, respectively (data not shown). Based on this, the high and low expression levels of the two indicators IL- 6 and miR-1271 were established, respectively, each with 35 cases. The 3 -year overall survival rate of patients with a low expression of IL- 6 was better than that of patients with a high expression in young gastric
Table III. Expression levels of IL-6 and miR-1271 in gastric cancer tissues and adjacent tissues.

\begin{tabular}{lrcc}
\hline Group & $\mathrm{n}$ & IL-6 & miR-1271 \\
\hline Adjacent tissues & 146 & $1.23 \pm 0.15$ & $3.06 \pm 0.26$ \\
Elderly gastric cancer tissues & 76 & $4.65 \pm 0.34^{\mathrm{a}}$ & $1.04 \pm 0.09^{\mathrm{a}}$ \\
Young gastric cancer tissues & 70 & $3.12 \pm 0.21^{\mathrm{a}, \mathrm{b}}$ & $1.82 \pm 0.18^{\mathrm{a}, \mathrm{b}}$ \\
F value & & 2042.00 & 2399.00 \\
P-value & & $<0.001$ & $<0.001$ \\
\hline
\end{tabular}

${ }^{\mathrm{a}} \mathrm{P}<0.001$, compared with adjacent tissues; ${ }^{\mathrm{b}} \mathrm{P}<0.001$, compared with elderly gastric cancer tissues.

cancer $(\mathrm{P}<0.05)$. Survival of patients with a high expression of miR-1271 was better than that of patients with a low expression in young gastric cancer $(\mathrm{P}<0.05)$. The median expression levels of IL-6 and miR-1271 in elderly gastric cancer patients were $4.63 \pm 0.24$ and $1.05 \pm 0.06$, respectively (data not shown). Based on this, the high and low expression levels of the indicators IL-6 and miR-1271 were established, 
Table IV. Correlation of IL-6 and miR-1271 expression levels with clinical and pathological features.

\begin{tabular}{|c|c|c|c|c|c|c|c|}
\hline Factor & $\mathrm{n}$ & IL-6 & $\mathrm{t}$ value & P-value & miR-1271 & $\mathrm{t}$ value & P-value \\
\hline Age (years) & & & 32.990 & $<0.001$ & & 32.680 & $<0.001$ \\
\hline$\geq 60$ & 76 & $4.65 \pm 0.34$ & & & $1.04 \pm 0.09$ & & \\
\hline$\leq 40$ & 70 & $3.12 \pm 0.21$ & & & $1.82 \pm 0.18$ & & \\
\hline Sex & & & 0.674 & 0.501 & & 1.382 & 0.169 \\
\hline Male & 94 & $3.64 \pm 0.28$ & & & $1.62 \pm 0.11$ & & \\
\hline Female & 52 & $3.61 \pm 0.21$ & & & $1.65 \pm 0.15$ & & \\
\hline Tumor size & & & 2.599 & 0.010 & & 2.237 & 0.027 \\
\hline$\geq 5 \mathrm{~cm}$ & 66 & $3.57 \pm 0.26$ & & & $1.42 \pm 0.15$ & & \\
\hline$<5 \mathrm{~cm}$ & 80 & $3.46 \pm 0.25$ & & & $1.48 \pm 0.17$ & & \\
\hline Lymph node metastasis & & & 18.080 & $<0.001$ & & 24.960 & $<0.001$ \\
\hline Yes & 72 & $4.03 \pm 0.29$ & & & $1.14 \pm 0.13$ & & \\
\hline No & 74 & $3.31 \pm 0.18$ & & & $1.79 \pm 0.18$ & & \\
\hline Distant metastasis & & & 25.610 & $<0.001$ & & 24.060 & $<0.001$ \\
\hline Yes & 45 & $4.58 \pm 0.37$ & & & $1.01 \pm 0.08$ & & \\
\hline No & 101 & $3.24 \pm 0.25$ & & & $1.65 \pm 0.17$ & & \\
\hline Clinical stage & & & 17.630 & $<0.001$ & & 23.820 & $<0.001$ \\
\hline $\mathrm{I}+\mathrm{II}$ & 88 & $3.67 \pm 0.28$ & & & $1.83 \pm 0.19$ & & \\
\hline III+IV & 58 & $4.62 \pm 0.37$ & & & $1.15 \pm 0.13$ & & \\
\hline Differentiation degree & & & 24.010 & $<0.001$ & & 25.830 & $<0.001$ \\
\hline Low-medium & 92 & $4.33 \pm 0.31$ & & & $1.24 \pm 0.10$ & & \\
\hline High & 54 & $3.21 \pm 0.19$ & & & $1.86 \pm 0.19$ & & \\
\hline
\end{tabular}

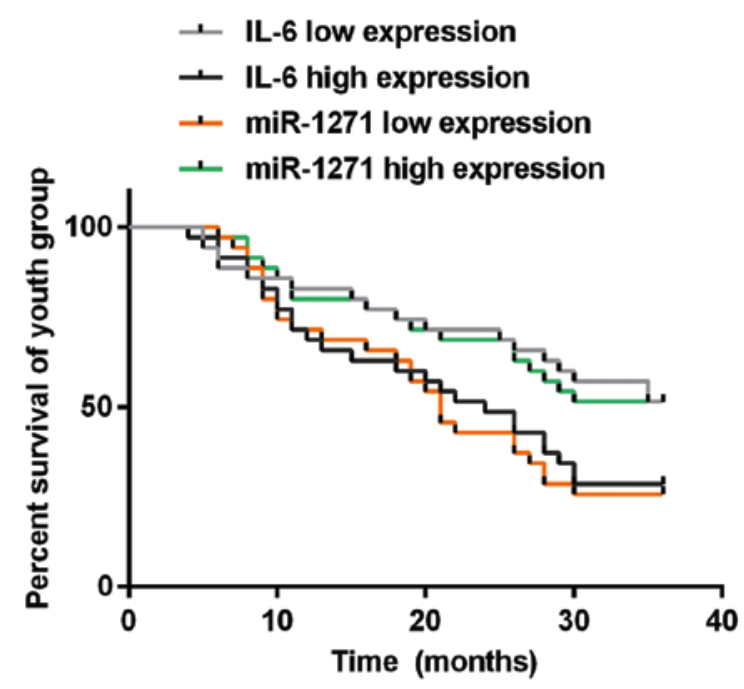

Figure 1. Correlation of expression levels of IL-6 and miR-1271 with prognosis of young gastric cancer. The results of Kaplan-Meier survival curve showed that the 3-year overall survival rate of patients with the low expression of IL- 6 was better than that of patients with the high expression in young gastric cancer $(\mathrm{P}=0.043)$. Survival of patients with high expression of miR1271 was better than that of patients with the low expression in young gastric cancer $(\mathrm{P}=0.025)$.

respectively, each with 38 cases. The 3 -year overall survival rate of patients with low expression of IL-6 was better than that of patients with high expression in elderly gastric cancer patients $(\mathrm{P}<0.05)$. That of patients with the high expression

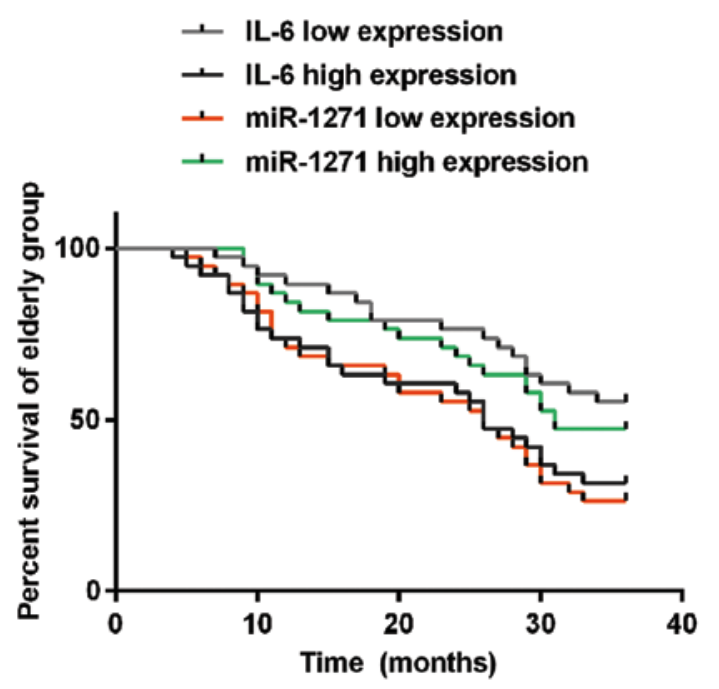

Figure 2. Correlation of expression levels of IL-6 and miR-1271 with prognosis of elderly gastric cancer. The results of Kaplan-Meier survival curve showed that the 3 -year overall survival rate of patients with the low expression of IL- 6 was better than that of patients with the high expression in elderly gastric cancer $(\mathrm{P}=0.021)$. Survival of patients with the high expression of miR-1271 was better than that of patients with the low expression in elderly gastric cancer $(\mathrm{P}=0.047)$.

of miR-1271 was better than that of patients with the low expression in elderly gastric cancer patients $(\mathrm{P}<0.05)$ as per the Kaplan Meier analysis and log-rank test (Figs. 1 and 2, and Table V). 
Table V. Correlation of expression levels of IL-6 and miR-1271 with young and elderly gastric cancer.

\begin{tabular}{|c|c|c|c|c|c|c|c|}
\hline \multirow[b]{2}{*}{ Group } & \multicolumn{2}{|c|}{ Indicator } & \multirow[b]{2}{*}{$\mathrm{n}$} & \multicolumn{3}{|c|}{ Survival rate $[(\mathrm{n}) \%]$} & \multirow[b]{2}{*}{ P-value } \\
\hline & & & & 1 year & 2 years & 3 years & \\
\hline \multirow[t]{4}{*}{ Youth group } & IL-6 & Low expression & 35 & $29(82.86)$ & $25(71.43)$ & $18(51.43)$ & 0.043 \\
\hline & & High expression & 35 & $24(68.57)$ & $17(48.57)$ & $10(28.57)$ & \\
\hline & $\operatorname{miR}-1271$ & Low expression & 35 & $25(71.43)$ & $15(42.86)$ & $9(25.71)$ & 0.025 \\
\hline & & High expression & 35 & $28(80.00)$ & $24(68.57)$ & $16(45.71)$ & \\
\hline \multirow[t]{4}{*}{ Elderly group } & IL-6 & Low expression & 38 & $34(89.47)$ & $29(76.32)$ & $21(55.26)$ & 0.021 \\
\hline & & High expression & 38 & $28(73.68)$ & $23(60.53)$ & $12(31.58)$ & \\
\hline & miR-1271 & Low expression & 38 & $27(71.05)$ & $21(55.26)$ & $10(26.32)$ & 0.047 \\
\hline & & High expression & 38 & $32(84.21)$ & $26(68.42)$ & $18(47.37)$ & \\
\hline
\end{tabular}

\section{Discussion}

Gastric cancer accounts for $10.4 \%$ of the total number of cancer deaths in Western countries (19). Currently, it is a comprehensive treatment based on surgery, but its local recurrence rate following surgery is still as high as $50 \%$, with poor postoperative survival rate (20). The formation of tumors mainly depends on the activation of proto-oncogenes and mutation of tumor suppressor genes. The development mechanism of gastric cancer has not yet been clarified, owing to the abnormal lack of specificity of the genes (21).

Nurul-Syakima et al (22) found that miR-1271 is highly expressed in head and neck tumors, but Maurel et al (23) reported a low expression in hepatoma cells, exerting a tumor suppressor effect. In this study, the expression level of miR-1271 was significantly lower in young and elderly gastric cancer tissues than that in adjacent tissues, with a statistically significant difference $(\mathrm{P}<0.001)$. That of miR-1271 was significantly higher in young gastric cancer tissues than that in elderly gastric cancer tissues, with a statistically significant difference $(\mathrm{P}<0.001)$. In addition, miR-1271 was not significantly correlated with sex $(\mathrm{P}>0.05)$, but was correlated with age, tumor size, lymph node metastasis, distant metastasis, clinical stage and differentiation degree of gastric cancer patients $(\mathrm{P}<0.05)$. Taken together, the above results indicate that the expression levels and roles of miR-1271 are different in different tumors, tissues and cells. The study of Xiang et al (24) shows that miR-1271 expression is low in gastric cancer tissues of most patients, and is negatively correlated with tumor size and clinical stage. Those findings are consistent with our results. In this study, data of the correlation analysis of miR-1271 with the clinical pathology of gastric cancer were presented as mean standard deviation, but as the number of cases in the studies were different, this may result in statistically significant differences due to different statistical calculation methods.

Our study showed that the expression level of IL-6 was significantly higher in young and elderly gastric cancer tissues than that in adjacent tissues, with a statistically significant difference $(\mathrm{P}<0.001)$. That of IL-6 was significantly lower in young gastric cancer tissues than that in elderly gastric cancer tissues, with a statistically significant difference $(\mathrm{P}<0.001)$. That of IL-6 was not significantly correlated with sex $(\mathrm{P}>0.05)$, but correlated with age, tumor size, lymph node metastasis, distant metastasis, clinical stage and differentiation degree of gastric cancer patients $(\mathrm{P}<0.05)$. The expression level of IL-6 was higher in elderly gastric cancer than that in young gastric cancer, probably because the elderly usually have low immune function, susceptible to inflammatory infections (25). Sampaio et al (26) found that IL-6, highly expressed in gastric cancer tissues, is correlated with tumor size and the T stage of gastric cancer. The results of this study are consistent with those of Sampaio et al (26). In this study, the data of the correlation analysis of IL-6 with the clinical pathology of gastric cancer were presented as mean standard deviation. According to reports in the literature, IL-6 affects the growth of tumor cells and the development of the disease (27). It also promotes angiogenesis, and the adhesion and invasion of tumor cells (28).

The 3-year overall survival rate of patients with the low expression of IL- 6 was better than that of patients with the high expression in young and elderly gastric cancer $(\mathrm{P}<0.05)$. Survival of patients with the high expression of miR-1271 was better than that of patients with the low expression in young and elderly gastric cancer $(\mathrm{P}<0.05)$. Since no study of the correlation of IL- 6 and miR-1271 with the prognosis of young and elderly gastric cancer was found, the results of this study cannot be compared with those of other studies.

In summary, IL-6 is highly expressed but miR-1271 is lowly expressed in gastric cancer tissues, and the expression levels of both are correlated with age, tumor size, lymph node metastasis, distant metastasis, clinical stage and differentiation degree of gastric cancer patients. The 3-year overall survival rate of patients with the low expression of IL-6 is better than that of patients with the high expression in young and elderly gastric cancer. Survival of patients with high expression of miR-1271 is better than that of patients with low expression in young and elderly gastric cancer.

\section{Acknowledgements}

Not applicable.

\section{Funding}

No funding was received. 


\section{Availability of data and materials}

The datasets used and/or analyzed during the current study are available from the corresponding author on reasonable request.

\section{Authors' contributions}

SL was involved in writing the manuscript. SL and YZ performed PCR. LZ and JWa were responsible for total RNA extraction and reverse transcription reaction. RJ collected and analyzed the general data of patients. YW, JWu and XY helped with ELISA. All authors read and approved the final manuscript.

\section{Ethics approval and consent to participate}

This study was approved by the Ethics Committee of The First Hospital of Lanzhou University (Lanzhou, China). Patients who participated in this research had complete clinical data. Signed informed consents were obtained from the patients or the guardians.

\section{Patient consent for publication}

Not applicable.

\section{Competing interests}

The authors declare that they have no competing interests.

\section{References}

1. Karim S, Mirza Z, Naseer MI, Al-Qahtani MH and Ali A: Clinicopathological characteristics and chronology of p53 expression in the development of gastric cancer. Hepatogastroenterology 60: 2113-2118, 2013.

2. Krejs GJ: Gastric cancer: Epidemiology and risk factors. Dig Dis 28: 600-603, 2010.

3. Dhobi MA, Wani KA, Parray FQ, Wani RA, Wani ML, Peer GQ, Abdullah S, Wani IA, Wani MA, Shah MA, et al: Gastric cancer in young patients. Int J Surg Oncol 2013: 981654, 2013.

4. Kim DY, Joo JK, Ryu SY, Park YK, Kim YJ and Kim SK: Clinicopathologic characteristics of gastric carcinoma in elderly patients: A comparison with young patients. World J Gastroenterol 11: 22-26, 2005.

5. Hsieh FJ, Wang YC, Hsu JT, Liu KH, Yeh CN, Yeh T-S, Hwang T-L and Jan Y-Y: Clinicopathological features and prognostic factors of gastric cancer patients aged 40 years or younger J Surg Oncol 105: 304-309, 2012.

6. Park HJ, Ahn JY, Jung HY, Lim H, Lee JH, Choi KS, Kim DH, Choi KD, Song HJ, Lee GH, et al: Clinical characteristics and outcomes for gastric cancer patients aged 18-30 years. Gastric Cancer 17: 649-660, 2014.

7. Kashiwagi Y, Kato N, Sassa T, Nishitsuka K, Yamamoto T, Takamura $\mathrm{H}$ and Yamashita H: Cotylenin A inhibits cell proliferation and induces apoptosis and PAX6 mRNA transcripts in retinoblastoma cell lines. Mol Vis 16: 970-982, 2010.

8. Tchernitsa O, Kasajima A, Schäfer R, Kuban RJ, Ungethüm U, Györffy B, Neumann U, Simon E, Weichert W, Ebert MP, et al: Systematic evaluation of the miRNA-ome and its downstream effects on mRNA expression identifies gastric cancer progression. J Pathol 222: 310-319, 2010.

9. Wang Y, Xu L and Jiang L: miR-1271 promotes non-small-cell lung cancer cell proliferation and invasion via targeting HOXA5. Biochem Biophys Res Commun 458: 714-719, 2015.
10. Naugler WE and Karin M: The wolf in sheep's clothing: The role of interleukin- 6 in immunity, inflammation and cancer. Trends Mol Med 14: 109-119, 2008.

11. Ashizawa T, Okada R, Suzuki Y, Takagi M, Yamazaki T, Sumi T, Aoki T, Ohnuma $S$ and Aoki T: Clinical significance of interleukin-6 (IL-6) in the spread of gastric cancer: Role of IL-6 as a prognostic factor. Gastric Cancer 8: 124-131, 2005.

12. Dey AB: World report on ageing and health. Indian J Med Res 145: 150-151, 2017.

13. Sasaki M, Ikeda H, Sato Y and Nakanuma Y: Proinflammatory cytokine-induced cellular senescence of biliary epithelial cells is mediated via oxidative stress and activation of ATM pathway: A culture study. Free Radic Res 42: 625-632, 2008.

14. Bartek J, Hodny Z and Lukas J: Cytokine loops driving senescence. Nat Cell Biol 10: 887-889, 2008.

15. Akbaraly TN, Hamer M, Ferrie JE, Lowe G, Batty GD, HaggerJohnson G, Singh-Manoux A, Shipley MJ and Kivimäki M: Chronic inflammation as a determinant of future aging phenotypes. CMAJ 185: E763-E770, 2013.

16. Gorelick PB: Role of inflammation in cognitive impairment: Results of observational epidemiological studies and clinical trials. Ann NY Acad Sci 1207: 155-162, 2010.

17. Satizabal CL, Zhu YC, Mazoyer B, Dufouil C and Tzourio C: Circulating IL-6 and CRP are associated with MRI findings in the elderly: The 3C-Dijon Study. Neurology 78: 720-727, 2012.

18. Livak KJ and Schmittgen TD: Analysis of relative gene expression data using real-time quantitative PCR and the 2(-Delta Delta C(T)) method. Methods 25: 402 408, 2001.

19. Guggenheim DE and Shah MA: Gastric cancer epidemiology and risk factors. J Surg Oncol 107: 230-236, 2013.

20. Paoletti X, Oba K, Burzykowski T, Michiels S, Ohashi Y, Pignon JP, Rougier P, Sakamoto J, Sargent D, Sasako M, et al; GASTRIC (Global Advanced/Adjuvant Stomach Tumor Research International Collaboration) Group: Benefit of adjuvant chemotherapy for resectable gastric cancer: A meta-analysis. JAMA 303: 1729-1737, 2010.

21. Skinnider BF and Mak TW: The role of cytokines in classical Hodgkin lymphoma. Blood 99: 4283-4297, 2002.

22. Nurul-Syakima AM, Yoke-Kqueen C, Sabariah AR, Shiran MS, Singh A and Learn-Han L: Differential microRNA expression and identification of putative miRNA targets and pathways in head and neck cancers. Int J Mol Med 28: 327-336, 2011.

23. Maurel M, Jalvy S, Ladeiro Y, Combe C, Vachet L, Sagliocco F, Bioulac-Sage P, Pitard V, Jacquemin-Sablon H, Zucman-Rossi J, et al: A functional screening identifies five microRNAs controlling glypican-3: Role of miR-1271 downregulation in hepatocellular carcinoma. Hepatology 57: 195-204, 2013.

24. Xiang XJ, Deng J, Liu YW, Wan LY, Feng M, Chen J and Xiong JP: MiR-1271 inhibits cell proliferation, invasion and EMT in gastric cancer by targeting FOXQ1. Cell Physiol Biochem 36: 1382-1394, 2015.

25. Judd LM, Alderman BM, Howlett M, Shulkes A, Dow C, Moverley J, Grail D, Jenkins BJ, Ernst M and Giraud AS: Gastric cancer development in mice lacking the SHP2 binding site on the IL-6 family co-receptor gp130. Gastroenterology 126: 196-207, 2004.

26. Sampaio AM, Balseiro SC, Silva MR, Alarcão A, d'Aguiar MJ, Ferreira T and Carvalho L: Association between IL-4 and IL-6 expression variants and gastric cancer among Portuguese population. GE Port J Gastroenterol 22: 143-152, 2015.

27. Ohi S, Hashimoto H, Tachibana T, Tabei I, Nakajima M, Sato K, Yanaga $\mathrm{K}$ and Ishikawa $\mathrm{H}$ : Establishment and characterization of EB virus-free normal B-lymphocyte and interleukin-6-producing poorly differentiated adenocarcinoma cell lines derived from gastric tumor tissue. Hum Cell 18: 35-44, 2005.

28. Huang SP, Wu MS, Wang HP, Yang CS, Kuo ML and Lin JT: Correlation between serum levels of interleukin- 6 and vascular endothelial growth factor in gastric carcinoma. J Gastroenterol Hepatol 17: 1165-1169, 2002.

This work is licensed under a Creative Commons Attribution-NonCommercial-NoDerivatives 4.0 International (CC BY-NC-ND 4.0) License. 